\title{
Alterations of Non Invasive Maternal Hemodynamics in Weeks 10 To 14 of Gestation Associated with Preeclampsia and Adverse Perinatal Results
}

\author{
Berenice Zavala-Barrios ${ }^{1 *}$, Juan Manuel Veléz-Reséndiz², Mónica Malagón-Gómez², Carlos Gabriel Briones- \\ Vega $^{4}$, Augusto Perez-Calatayud ${ }^{5}$ and Jésús Carlos Briones-Garduño ${ }^{6}$
}

${ }^{1}$ Medicina Materno Fetal en el Hospital General de México, Mexico

${ }^{2}$ Department of Cardiology, Medicina Materno Fetal en el Hospital General de México, Mexico

${ }^{3}$ Medicina Materno Fetalenel Hospital Generalde México, Mexico

${ }^{4}$ Adscrito en Unidad Materno Fetal INGENES CDMX, Mexico

${ }^{5}$ Terapia Intensiva de Ginecología y Obstetricia del Hospital General de México, Mexico

${ }^{6}$ Académico de Número de la Academia Mexicana de Medicina, Mexico

Submission: January 07, 2020; Published: January 21, 2020

*Corresponding author: Berenice Zavala-Barrios, Medicina Materno Fetal en el Hospital General de México, Mexico

\begin{abstract}
Background: Normal pregnancy represents a unique local immunomodulation phenomenon, in which there is a natural tolerance between two antigenically disparate tissues, the maternal environment requires a hemodynamic and physiological adaptation of pregnancy tolerability.

Objective: To evaluate the association between hemodynamic alterations in the mother caused by placental adaptation during the first trimester against adverse perinatal outcomes.

Materials and Methods: A nested case-control study was conducted in a cohort at the General Hospital of Mexico "Dr. Eduardo Liceaga "the collection of patients was performed during 2016 and 2017. All pregnant patients were included in week 10 to 14 of pregnancy, and were distributed in case groups (patients at high risk of preeclampsia) and controls ( healthy), those patients that hemodynamic measurement was not possible were excluded and those who did not complete the monitoring and resolution in the hospital were eliminated. The hemodynamic variables were measured: cardiac output (CO), cardiac index (CI), peripheral vascular resistance (PVR) and peripheral vascular resistance index (IRVP), this with non-invasive hemodynamics using USCOM, at the end of pregnancy the result was recorded perinatal The statistical analysis was performed with Moses extreme reaction and linear regression to find the associations, when finding this association, cut points were developed by ROC curves for the hemodynamic variables and by contingency tables (Odds Ratio) the risk possibilities were established of adverse perinatal outcomes according to these cutoff points.
\end{abstract}

Result: The cohort consisted of 93 patients, two groups were distributed (low and high risk), when the hemodynamic variables were found in the cutoff points GC 5.5lt, IC 3lt., RVP 1200din and IRVP 2500din, by means of test Moses of extreme reaction is observed p $<0.05$ in association of the development of preeclampsia, perinatal death and of gestational diabetes. In linear regression to evaluate PVR and GC, with presence of preeclampsia $r 2=0.857(\mathrm{p}<0.008)$; gestational diabetes $r 2=0.865$, $(\mathrm{p}<0.05)$; Adverse perinatal result $\mathrm{r} 2=0.803$, $(\mathrm{p}<0.05)$; and perinatal death $\mathrm{r} 2=0.969$, $(\mathrm{p}<0.011)$. IC $<3 \mathrm{lt}$ and IRVP $>2500 \mathrm{din}$. In the risk possibilities in IC $<2.5 \mathrm{lt}$. presented $\mathrm{OR}=2.4$ to develop an overall adverse perinatal result ( $\mathrm{p}<0.049$ ), $83 \%$ of the patients with preeclampsia had IC $<31$ t.

Conclusion: In our cohort there is an association between hemodynamic alterations from the 1st trimester of pregnancy and adverse perinatal outcomes. We found that the IC $<3$ lt obtained a sensitivity of $78 \%$ and a specificity of $66 \%$ to detect such adverse perinatal results (OR 1.46), to develop gestational diabetes (OR 2.4) and $83 \%$ of preeclampsia. The cut-off points to consider as risk of adverse perinatal outcomes in our hemodynamic variables were RVP> $1200 \mathrm{din}$, IRVP $>2500 \mathrm{din}$, IC $<3$ lt and GC $<5.51$.

Keywords: Maternal hemodynamics; Adverse perinatal outcome; Preeclampsia; Gestational diabetes; Perinatal death 


\section{Introduction}

Normal pregnancy represents a phenomenon of unique local immunomodulation in which there is a natural tolerance between two antigenically disparate tissues [1]. This phenomenon of immunological tolerance essentially occurs at the local level, at the uteroplacental interface. There are probably several factors involved in it [2].including placental implantation.

\section{Preeclampsia and Hemodynamic Adaptation}

Preeclampsia is a multisystemic syndrome of variable severity that is specific to pregnancy and is characterized by a reduction in systemic perfusion generated by vasospasms and the activation of coagulation systems. It occurs after week 20 of pregnancy, during delivery or in the first 6 weeks after delivery [3]. When implantation occurs, changes in hemodynamics begin that have been clinically described in multiple studies. Blood flow during pregnancy and cardiac output (CO) begin to increase during the first trimester under normal conditions, probably due to an increase in the heart rate and systolic volume, as well as a decrease in blood viscosity and the vasodilatory actions of the hormones produced by the fetoplacental unit $[3,4]$.

Current knowledge assumes that normal placental implantation represents a physiological state of immunotolerance based on, among other possible factors that have not yet been identified, special antigenic expression and a local balance of cytokines [5,6]. This aberrant immunotolerance eventually manifests itself through preeclampsia, gestational diabetes and some adverse perinatal outcomes (Figure 1).

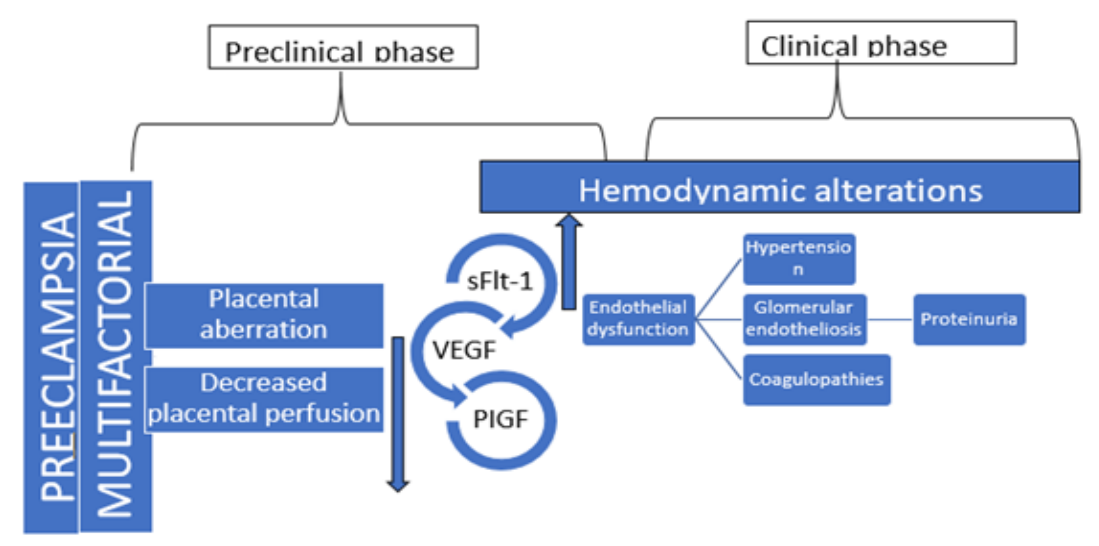

Figure 1: Preclinical and clinical phases of preeclampsia

\section{Prediction of Perinatal Outcomes}

Adverse perinatal results constitute a health problem that, as noted in the most recent bulletin issued by the WHO, must be addressed. Recent studies have investigated placental alterations that induce apoptosis, vascular alterations and endothelial damage, which in turn cause fetal morbidity [7]. Scientific advances over the past 20 years have increased hope that many of the complications of pregnancy could be detectable from at least 12 weeks of gestation [8].

It is also increasingly evident that a complete hospital visit at weeks 11 to 13 for the purpose of combining data on the mother's characteristics and history with the results of biophysical and biochemical tests can define the patient's specific risks for a wide range of complications in pregnancy, including miscarriage and intrauterine fetal demise, premature birth, preeclampsia, gestational diabetes, fetal growth restriction and macrosomia [9]. Current evidence suggests that the pathophysiology of growth restriction and preeclampsia is closely related to the imbalance between angiogenic and antiangiogenic proteins [10]. present since the beginning of pregnancy, something that is measurable for screening purposes [11,12]. from weeks 11 to 14 of gestation. Ultrasonic Cardiac Output Monitor (USCOM) Use in

\section{Pregnancy}

The USCOM is an ultrasonic cardiac performance monitor that has recently been available in clinical practice. It works by measuring the rate of pulmonary or aortic blood flow. Validated internal algorithms calculate the diameter of the aortic and pulmonary valves according to the height and weight of the patient. In the hands of an experienced user, the USCOM provides CO readings with an accuracy rate on the order of $98 \%$. It is considered the most accurate method of measuring $\mathrm{CO}$ and peripheral vascular resistance (RVP) in clinical practice, and it is far superior to other methods, such as pulmonary artery catheterization (Swan-Ganz) [13]. 


\section{Historical Background on Hemodynamics in Preg-} nancy

History indicates the occurrence of some analyses of the behavior of the fetal state, despite the fact that some anatomical aspects of the fetal circulation had already been described by Galen [14]. In 1956, Satomura [15] published the first research on Doppler applications for a study of vascular flows. Fitzgerald and Drumm, [16] in 1977, evaluated umbilical flow through this procedure for the first time. In recent years, the application of the Doppler effect, as a complement to conventional ultrasound, has allowed for the evaluation of fetal hemodynamics in a noninvasive way.

Another study conducted in 2013 by Anne Marijin van der Graaf et al. [17] proposes a Doppler device called the SphygmoCor to monitor the pulse wave of the radial artery as well as the USCOM for use as reliable, easy-to-use, non-invasive methods of hemodynamic evaluation during pregnancy. The study also found a correlation between alterations in cardiac output and peripheral vascular resistance, which, in cases of maladaptive placentas, can be detected with these methods from the first trimester of pregnancy.

Recently, in February 2015, Tiralongo et al. [18] described cardiovascular effects of pregnancy in the first trimester that are associated with hypertensive syndromes. These evaluations were performed using the USCOM, and their results showed that the RVP is elevated in the first trimester in normotensive patients and that this measure can be a predictive marker of preeclampsia. Other non-invasive methods like the USCOM have revealed the same hemodynamic pattern in severe preeclampsia. Adverse perinatal outcomes are another health problem that was noted as a problem to be addressed in the latest bulletin issued by the WHO $[7,19]$.

Technology has helped to improve the understanding of the mechanisms of the development of hypertensive disorders in pregnancy and fetal damage, which has led to an attempt to predict the catastrophic events that occur in each condition. We attempt to demonstrate that the measurement of hemodynamic variables in pregnant women through the USCOM can be a useful predictive tool for adverse perinatal outcomes. Its cost compared to assessments of other markers is lower and its reproducibility is simple; however, as we have seen in the introduction, more research is needed to support the results obtained and to establish cut-off points in the population, which is why the present work has been developed. Furthermore, one of the new objectives of the millennium is to reduce maternal and fetal morbidity and mortality.

\section{Materials and Methods}

A nested case-control study was conducted within a cohort. The sample number was calculated based on this statistical design. Pregnant women who attended the prenatal clinic in the Gynecology and Obstetrics Unit of the Mexico General Hospital, of any age, who were between week 10-14 of gestation and who agreed to enter the study by signing the informed consent form were included and registered. The groups were distributed according to the inclusion criteria. Measurements of hemodynamic behavior were performed using USCOM on pregnant patients in weeks 10 to 14 of their pregnancies. These measures included the cardiac output (CO), cardiac index (CI), peripheral vascular resistance (PVR), and peripheral vascular resistance index (PVRI). The measurement technique was as follows: patients were registered with their file numbers; their weight, height, and saturation values were then recorded [10]. Subsequent followups and prenatal controls were carried out in accordance with the corresponding clinical practice guidelines. At the end of each pregnancy, maternal and fetal outcomes were evaluated.

These results were stratified and classified according to the hemodynamic behavior. The associations between the values measured with the USCOM and the development of the independent variables were analyzed by means of descriptive statistics for the expression of the results with the frequency distribution, thus yielding absolute frequencies (number of cases), relative frequencies (percentages), and adjusted and accumulated frequencies. Inferential or comparative statistics were obtained using Student's Xi2 or t-tests based on the frequency distribution curve. Contingency tables were carried out that determined the sensitivity, specificity and predictive values of the test. The linear quadratic regression was performed using SPSS version 22 (IBM, Armonk, NY, USA).

Result

Table 1: Homogeneity in the characterization of the groups is demonstrated by the results of student's t-test between the low- and high-risk groups. It is observed that the hemodynamic pattern of the CO, Cl, RVP and RVPI is not different between the groups, which suggests that the hemodynamic alteration is due to an intrinsic factor of pregnancy.

\begin{tabular}{|c|c|c|c|c|}
\hline & $\begin{array}{c}\text { Low-Risk Group } \\
\mathbf{N} \mathbf{6 2 / 9 3}\end{array}$ & $\begin{array}{c}\text { High-Risk Group } \\
\mathbf{N}: \mathbf{3 1 / 9 3}\end{array}$ & Total & P Value \\
\hline Age & $26.1(26.1-27.8)$ & $28.5(26.3-30.7)$ & $27(14-42)$ & 0.102 \\
\hline BMI & $26.0(25.9-27.1)$ & $26.1(24.3-27.7)$ & $26.14(18.06-39.30)$ & 0.93 \\
\hline Weight & $63.5(61.0-66.3)$ & $61.3(57.3-65.2)$ & $63.01(42.3-94.0)$ & 0.346 \\
\hline EG & $12.9(12.6-13.1)$ & $12.4(12.1-12.6)$ & $12.771(11.0-14.2)$ & $0.008^{*}$ \\
\hline
\end{tabular}




\section{Journal of Gynecology and Women's Health}

\begin{tabular}{|c|c|c|c|c|}
\hline TAM & $77.7(76.4-79.9)$ & $82.2(79.2-85.8)$ & $79.62(61.67-103.3)$ & $0.010^{*}$ \\
\hline TAS & $104.4(102-107)$ & $109.7(105-113)$ & $106(80-130)$ & $0.023^{*}$ \\
\hline TAD & $64.4(63.0-66.6)$ & $68.5(65.2-71.9)$ & $66(50-91)$ & $0.023^{*}$ \\
\hline CO & $4.6(4.3-4.8)$ & $4.4(4.1-4.7)$ & $4.5(2.8-9.4)$ & 0.516 \\
\hline CI & $2.77(2.6-2.9)$ & $2.70(2.5-2.9)$ & $2.7(1.4-4.4)$ & 0.638 \\
\hline RVPI & $\begin{array}{c}2380 \\
(2244-2582)\end{array}$ & $\begin{array}{c}2526 \\
(1528-2720)\end{array}$ & $2446(1298-5196)$ & 0.301 \\
\hline RVP & 1428 & $1469(742-2519)$ & 0.204 \\
\hline
\end{tabular}

Table 2: Chi2 statistic. This compares the low- and high-risk groups against the presence of preeclampsia, gestational diabetes, perinatal death and adverse perinatal outcomes, without significant differences observed.

\begin{tabular}{|c|c|c|}
\hline Outcome & Chi $^{\mathbf{2}}$ & P value \\
\hline Preeclampsia & 0 & 1 \\
\hline Gestational diabetes & 0.74 & 0.442 \\
\hline Perinatal death & 1.93 & 0.271 \\
\hline Adverse perinatal outcome & 0.85 & 0.369 \\
\hline
\end{tabular}

The sample size was 93 patients based on the methodology. Two groups were established: a low-risk group (controls) and a highrisk group (cases). The case-control ratio was established as 1:2. A total of 62 patients were obtained for the control or low-risk group, and 31 were placed in the case or high-risk group. The descriptive statistics for the low-risk group were mean age of 26.1 years, body mass index (BMI) of 26 , weight of $63.5 \mathrm{~kg}$ and gestational age of 12.9 weeks. The high-risk group had a mean age of 28.5 years, BMI of 26.1, weight of $61.3 \mathrm{~kg}$ and gestational age of
12.4 weeks. A comparison of the averages between both groups did not find any significant differences except for the gestational age (Table 1). When observing the results of the cohort (n: 93) the development of diabetes was observed in $23.7 \%$ (n: 22), preeclampsia in 6\% (n: 6), adverse perinatal outcomes in 35.5\% (n: 33 ) and perinatal death in $7.5 \%(n=7)$. No significant differences were found when the $\mathrm{Chi}^{2}$ test was performed between the lowand high-risk groups (Table 2).

Table 3: Results of the ROC curve in terms of the sensitivity and specificity of different cut-off points for the independent variables.

\begin{tabular}{|c|c|c|c|c|}
\hline Cut-Off Point & Preeclampsia & Gestational Diabetes & Perinatal Death & Adverse Perinatal Outcomes \\
\hline \multirow{2}{*}{ CO (5 liters) } & S: 83 & S: 81 & S: 85 & S: 84 \\
\hline & E: 85 & E: 85 & E: 84 & E: 85 \\
\hline \multirow{2}{*}{ CI (3 liters) } & S: 83 & S: 77 & S: 85 & S: 78 \\
\hline & E: 70 & E: 69 & E: 69 & E: 66 \\
\hline \multirow{2}{*}{ RVPI (2500 dynes) } & S: 50 & S: 63 & S: 71 & S: 51 \\
\hline & E: 36 & E: 63 & E: 36 & E: 73 \\
\hline \multirow{2}{*}{ RVP (1200 dynes) } & S: 83 & S: 72 & S: 85 & S: 78 \\
\hline & E: 77 & E: 78 & E: 76 & E: 76 \\
\hline
\end{tabular}




\section{Journal of Gynecology and Women's Health}

Table 4: Determination of ORs of independent variables with the presence of Cls of less than 2.5 and 3 liters.

\begin{tabular}{|c|c|c|c|c|c|}
\hline Variable & $\begin{array}{c}\text { Groups \% } \\
<3: \text { n } 58 \\
>3: \text { n } 35\end{array}$ & OR & $\mathbf{R R}$ & $\mathbf{C h i}^{2}$ & Moses test of extreme reaction \\
\hline \multirow{2}{*}{ Gestational diabetes } & $<3: 81.8$ & 0.287 & 2.4 & \multirow{2}{*}{$0.043^{*}$} & \multirow{2}{*}{0} \\
\hline & >3: 18.2 & $(0.88-0.93)$ & $(0.95-6.05)$ & & \\
\hline \multirow{2}{*}{ Preeclampsia } & $<3: 83$ & 3.2 & 2.7 & \multirow{2}{*}{0.29} & \multirow{2}{*}{0} \\
\hline & $>3: 17$ & $(0.35-28.6)$ & $(0.33-22.8)$ & & \\
\hline \multirow{2}{*}{ Adverse perinatal outcomes } & $>2.5: 16.1$ & 2.4 & 1.46 & \multirow{2}{*}{$0.046^{*}$} & \multirow{2}{*}{0} \\
\hline & $<2.5: 19.4$ & $(1.46-5.73)$ & $(0.96-2.22)$ & & \\
\hline \multirow{2}{*}{ Perinatal death } & $>2.5: 5.5$ & 2.03 & 1.41 & \multirow{2}{*}{0.36} & \multirow[b]{2}{*}{0} \\
\hline & $<2.5: 10.5$ & $(0.42-9.68)$ & $(0.59-3.37)$ & & \\
\hline
\end{tabular}

\section{ROC curve}

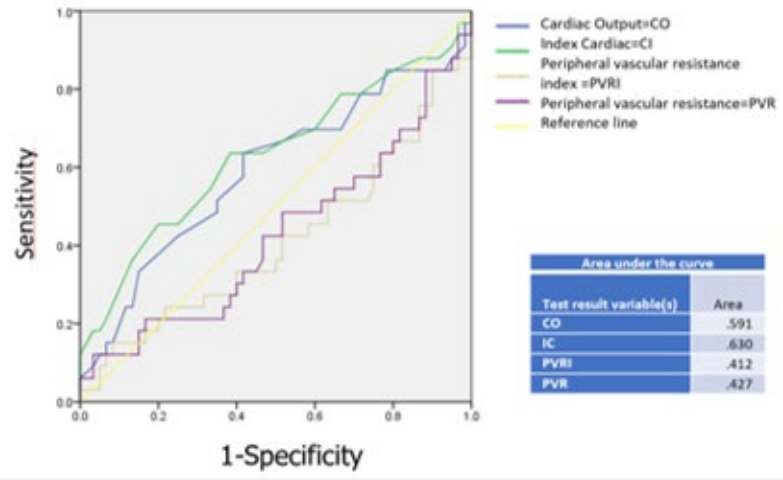

Figure 2: ROC curve for hemodynamic variables with respect to adverse perinatal outcomes. This showed a sensitivity and specificity of $78 \%$ and $66 \%$, respectively, with a cut-off point for the $\mathrm{Cl}$ of $3 \mathrm{l} / \mathrm{s}$

Comparative subgroup analyses were performed for each hemodynamic variable according to the cut-off points established by the ROC curves, with greater sensitivity and specificity values for the development of the independent variables (Figure $2 \&$ Table 3 ) found for the case of a CI of less than and greater than 3 liters. To establish this cut-off point, an ROC curve was made that gave a sensitivity and specificity for adverse outcomes of $78 \%$ and $66 \%$, respectively. It was observed that when applying the $\mathrm{Chi}^{2}$ test, the $p$ value was significant for the appearance of preeclampsia and the development of gestational diabetes when the CI was less than 3 . If this is established at a value of less than 2.5, it is significant for the development of adverse perinatal outcomes; similarly, in the Moses test for the direction of the distributions, statistical significance is observed for all of the variables (Table 4).

With a cut-off point of the systemic RVP of 1200 dynes, the odds ratios (ORs) and the relative risks (RRs) were as follows: gestational diabetes (OR 0.7, RR 1.07), preeclampsia (OR 2.01, RR 1.72), adverse perinatal outcomes (OR 1.72, RR 1.49) and perinatal death (OR 2.27, RR 1.92); however, the p-value was not significant. When ORs were found that were suggestive of risk but not significant, and with consideration for the percentage distribution by group, a Moses test of extreme reaction was performed to find that the distributions of each group maintained a different meaning, with each having a significant $\mathrm{p}$ value (Table 5) (Figure $3 \& 4$ ). 
Table 5: Association of variables with the presence of RVP >1200 dynes.

\begin{tabular}{|c|c|c|c|c|c|}
\hline Variable & $\begin{array}{c}\text { Groups \% } \\
<1200: \text { n } 26 \\
>1200: \text { n } 67\end{array}$ & OR & $\mathbf{R R}$ & $\mathrm{Chi}^{2}$ & $\begin{array}{l}\text { Moses test of ex- } \\
\text { treme reaction }\end{array}$ \\
\hline \multirow{2}{*}{ Gestational diabetes } & $<1200$ d: 26.9 & 0.78 & 1.07 & \multirow{2}{*}{0.64} & \multirow{2}{*}{0} \\
\hline & >1200 d: 22.4 & $(0.27-2.2)$ & $(0.78-1.4)$ & & \\
\hline \multirow{2}{*}{ Preeclampsia } & $<1200$ d: 3.8 & 2.01 & 1.72 & \multirow{2}{*}{0.52} & \multirow{2}{*}{0} \\
\hline & >1200 d: 7.5 & $(0.22-18.1)$ & $(0.27-10.6)$ & & \\
\hline \multirow{2}{*}{$\begin{array}{l}\text { Adverse perinatal } \\
\text { outcomes }\end{array}$} & <1200 d: 21.1 & 1.72 & 1.49 & \multirow{2}{*}{0.28} & \multirow{2}{*}{0} \\
\hline & >1200 d: 35.5 & $(0.63-4.66)$ & $(0.70-3.17)$ & & \\
\hline \multirow{2}{*}{ Perinatal death } & <1200 d: 3.8 & 2.27 & 1.92 & \multirow{2}{*}{0.44} & \multirow{2}{*}{0} \\
\hline & $>1200$ d: 9 & $(0.26-19.83)$ & $(0.30-12.1)$ & & \\
\hline
\end{tabular}
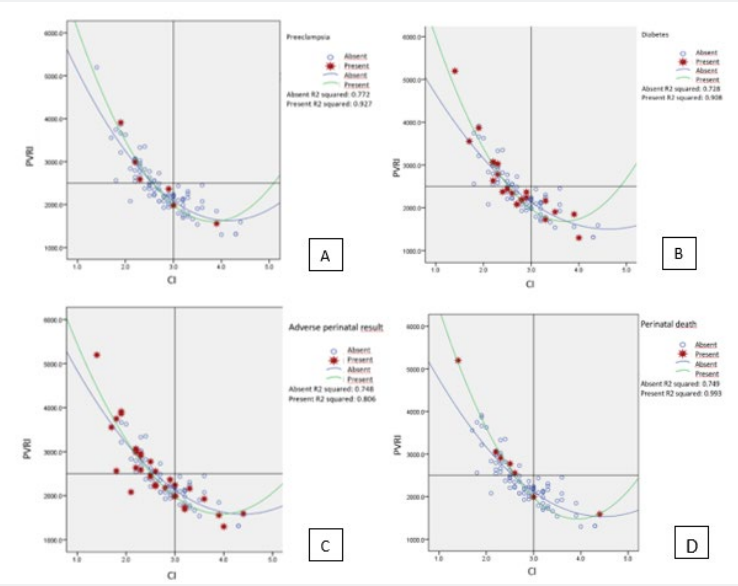

Figure 3: Quadratic linear regressions and associations of the RVPI and the $\mathrm{Cl}$ in the presence of $\mathrm{A})$ preeclampsia $(\mathrm{r} 2=0.927, \mathrm{p}=$ $0.011), B)$ gestational diabetes $(r 2=0.908, p=0.000), C)$ adverse perinatal outcomes $(r 2=0.806, p=0.000)$, and $D)$ perinatal death $(r 2$ $=0.993, p=0.011)$. Also presented are the means used as cut-off points for both the RVPI and $\mathrm{Cl}$ for each group.

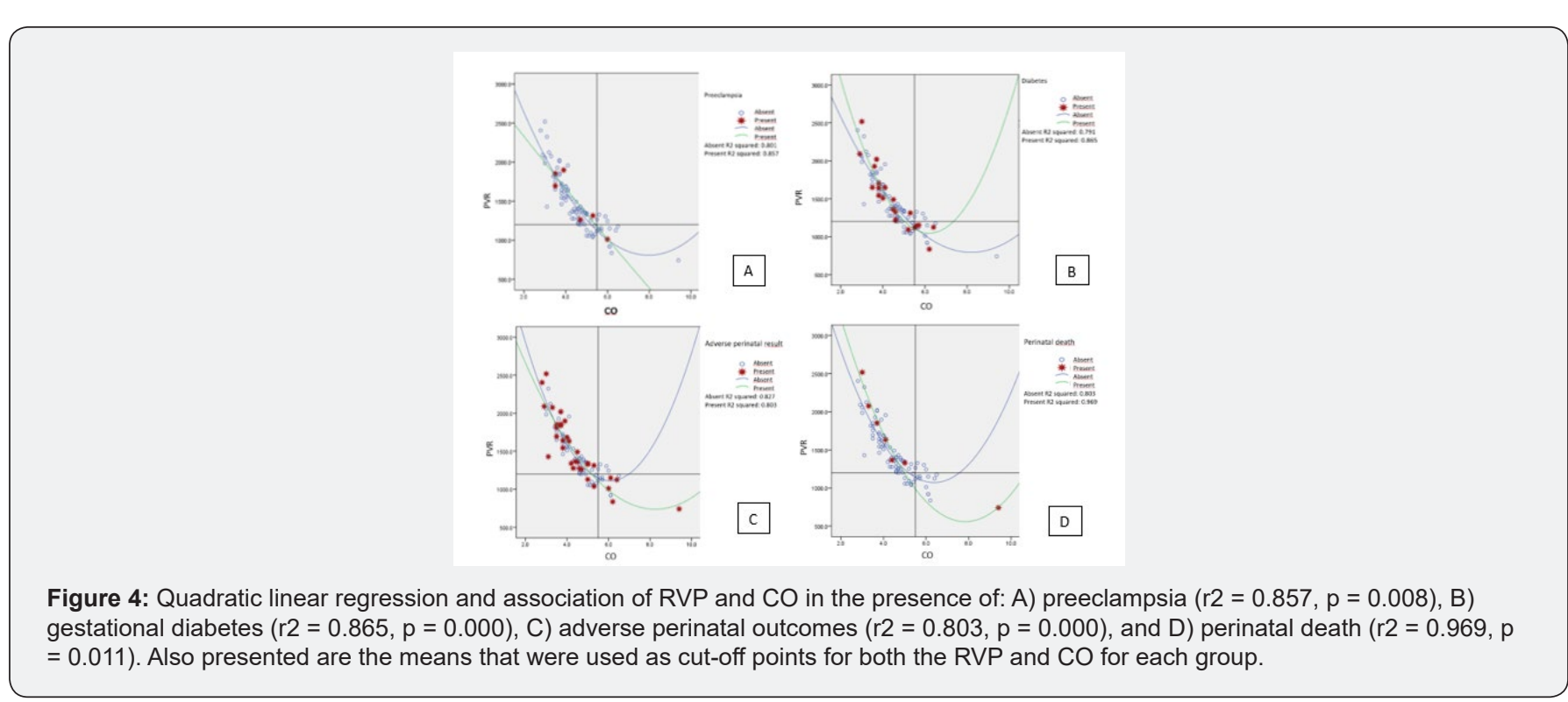


To give greater strength to the previous results, a linear regression was performed in search of an association between the peripheral vascular resistance (RVP) and CO, and the curve of greatest association turned out to be quadratic. Thus, it was performed for preeclampsia: $\mathrm{r} 2=0.857, \mathrm{p}=0.008$; gestational diabetes: $r 2=0.865, \mathrm{p}=0.000$; adverse perinatal outcomes: $\mathrm{r} 2=0.803, \mathrm{p}=0.000$; and perinatal death: $\mathrm{r} 2=0.969, \mathrm{p}=0.011$. Regarding a CI of less than 3 and an RVPI of greater than 2500, an association was found by means of a linear quadratic regression for preeclampsia ( $\mathrm{r} 2=0.927, \mathrm{p}=0.011)$, gestational diabetes ( $\mathrm{r} 2=0.908, \mathrm{p}=0.000)$, adverse perinatal outcomes ( $\mathrm{r} 2=0.806$, $\mathrm{p}=0.000)$, and perinatal death $(\mathrm{r} 2=0.993, \mathrm{p}=0.011)$.

Student's t-test was performed to evaluate the results of live newborns in terms of gestational age (Capurro), weight and height, contrasted by group (cases and controls), distributing the population between groups with RVPs greater than 1200 dynes and less than 1200 dynes and p-values greater than 0.05 (Table 6).

Table 6: Differences in means of neonatal results in the low- and high-risk groups, and in the groups with less than and more than 1200 dynes of RVP.

\begin{tabular}{|c|c|c|c|}
\hline & Low-Risk Group & High-Risk Group & Significance \\
\hline Capurro & 37.6 & 35.4 & $0199(-1.19-5.59)$ \\
\hline Weight & 2905 & 2732 & $0.278(-145.3-490.0)$ \\
\hline Size & 48.8 & 48.7 & $0.832(-1.19-1.48)$ \\
\hline Apgar 5' & 8.5 & 7.5 & $0.12(-0.26-2.13)$ \\
\hline Capurro & $<1200$ & $>1200$ & Significance \\
\hline Weight & 37.4 & 36.89 & $0.721(-2.3-3.45)$ \\
\hline Size & 2867.3 & 2854 & $0.915(-235-262)$ \\
\hline Apgar 5' & 48.8 & 48.7 & $0.909(-1.2-1.4)$ \\
\hline
\end{tabular}

\section{Analysis and Discussion of Result}

It has been established that a $10 \%$ increase in initial blood pressure levels carries the risk of developing preeclampsia, growth restriction [20], death and gestational diabetes [21]; our results are similar to those reported in the literature. However, when comparing the hemodynamic variables, no significant differences were observed between these groups, which suggests that the hemodynamic alterations may be caused by an intrinsic disorder of pregnancy that leads to an imbalance during the course of pregnancy. This would explain why not all high-risk patients develop preeclampsia or adverse perinatal outcomes associated with placental insufficiency. Several publications have shown this tendency towards placental insufficiency [22]. In contrast to what is reported, we established cut-off points to determine subgroups that have associations with preeclampsia, gestational diabetes, adverse perinatal outcomes, and perinatal death. These cut-off points were: a CO of 5.5 liters, a CI of 3 liters, a RVP of 1200 dynes and an RVPI of greater than 2500 dynes. We found that there is a risk probability of developing preeclampsia, adverse perinatal outcomes and perinatal death in the specific case of a cardiac index of less than 3 , given that in our cohort the probability of developing gestational diabetes increased 2.4 times $(\mathrm{p}=0.043)$. Furthermore, the risk of preeclampsia in this group was $83 \%$. If this cut-off point is reduced to 2.5 liters, a risk probability of 1.46 of developing adverse perinatal outcomes is obtained. To differentiate the directions of these groups as risk factors, the Moses test of extreme reaction was applied, in which significant differences were found in relation to the size of the sample. This pattern of a decreased CO and CI and elevated RVP has been observed in several publications associated mainly with preeclampsia [12,19,23], but some descriptions of this pattern are also found in the development of growth restrictions [23] and intrauterine death or early infertility [24]. However, it is worth mentioning that these publications only mention the trend; in our work, we determined specific values for our population of those at 10 to 14 weeks of gestation. We identified the associations of our dependent variables with independent variables and observed a strong association with statistically significant weight for a low CO of 5.5 with a RVP greater than 1200 dynes and a low CI (less than 3 liters) with a high RVPI (over 2500 dynes) in the development of gestational diabetes, preeclampsia, adverse perinatal outcomes (intrauterine growth restriction, prematurity, embryonic and fetal death) and perinatal death; however, unlike what has been reported in the literature $[12,19]$, the results of live births from this field did not show significant differences in terms of Capurro, Apgar, size and weight findings. It is worth mentioning that fetuses under 20 weeks were not included, so these results may be biased.

\section{Conclusion}

We suggest that the absence of hemodynamic differences between low- and high-risk groups in developing alterations such as preeclampsia, gestational diabetes, adverse perinatal outcomes and perinatal death are somewhat intrinsic to pregnancy, which in turn will depend on the physiological tolerability of each pregnant woman. A CI of lower than 3 obtained a sensitivity of $78 \%$ and specificity of $66 \%$ in detecting adverse perinatal outcomes, with a 
probability of 1.46 times more of developing them. With this value, there is a 2.4 times greater probability of developing gestational diabetes, and $83 \%$ of those who developed preeclampsia had this value between weeks 10 and 14 . The pattern of a high systemic RVP (greater than 1200 dynes), high RVPI (greater than 2500 dynes), low CI (less than 3 liters) and low CO (less than 5.5 liters), measured at weeks 10 through week 14 , has a statistically significant association with preeclampsia, adverse perinatal outcomes, gestational diabetes and perinatal death.

\section{Acknowledgement}

We appreciate the facilities granted by the National Polytechnic Institute and the General Hospital of México, as well as the residents in gynecology and obstetrics and maternal-fetal medicine for their contributions to the collection of patients.

\section{References}

1. Billington WD (1992) The normal fetomaternal immune relationship. Baillieres Clin Obstet Gynaecol 6(3): 417-438.

2. Chaouat G, Menu E, Delage G, Moreau JF, Khrishnan L, et al. (1995) Immuno-endocrine interactions in early pregnancy. Hum Reprod 10(Suppl 1): 55-59.

3. Bosio P, McKenna P, Conroyb R, O'Herlihy C (1999) Maternal central hemodynamics in hypertensive disorders of pregnancy. Obstet Gynecol 94(6): 978-984

4. Cooray GH (1945) The relation of arterial blood pressure to successive pregnancies among a rural population in Ceylon. Ind Med Gaz 80: 614616

5. Gall SA (1983) Maternal adjustments in the immune system in normal pregnancy. Clin Obstet Gynecol 26(3): 521-536.

6. Tzen B, Endressen MJ, Clausen T, Henriksen T (1994) Fasting serum triglycerides are increased before 20 weeks of gestation in women who later develop preeclampsia. Hypertens Preg 13(1): 103-109.

7. Rodríguez M, Couve-Pérez C, Martín SS, Martínez F, Lozano C, et al. (2017) Perinatal outcome and placental apoptosis in patients with late onset of preeclampsia and Doppler of the abnormal uterine artery at the time of diagnosis. Ultrasound Gynecol 51(6): 775-782.

8. Nicolaides KH (2011) Screening for fetal aneuploidies at 11 to 13 weeks. Prenat Diagn 31(1): 7-15.

9. Syngelaki A, Chelemen T, Dagklis T, Allan L, Nicolaides KH, et al. (2011) Challenges in the diagnosis of fetal non-chromosomal abnormalities at 11-13 weeks. Prenat Diagn 31(1): 90-102.

10. Khalil A, Arnaoutoglou C, Pacilli M, zabo SA, David AL, et al. (2012) Outcome of fetal exomphalos diagnosed at 11-14 weeks of gestation. Ultrasound Obstet Gynecol 39(4): 401-406.
11. Meneses C, Diaz de Leon P, Moreno S, Gonzalez D, Amezola C, et al. (2007) Measurement of hemodynamic values in normoevolutive pregnancy and immediate puerperium by thoracic bioimpedance. Rev Asoc Mex Med Crit and Ter Int 21(3): 149-153.

12. Meneses C, Moreno S, Gonzalez D, Díaz de Leon P, Rodriguez R, et al. (2008) Hemodynamic measurement in severe preeclampsia. Rev Asoc Mex Med Crit and Ter Int 22(1): 10-14.

\section{3. https://www.uscom.com.au/products/}

14. Salvesen K, Lees C, Abramowicz J, Brezinka C, Har TG, et al. (2011) ISUOG statement on the safe use of Doppler in the 11 to $13+6$-week fetal ultrasound examination. Ultrasound Obstet Gynecol 37(6): 628.

15. Satomura S (1959) A study of flow patterns in arteries in ultrasonic. J Aconstical Soc Jap 15: 151.

16. Fitzgerald DE, Drumm JE (1977) Non invasive measurement of human fetal circulation using ultrasound a new method. Br Med J 2(6100): $1450-1451$.

17. Marijin van der Graaf A, Zeeman GG, Groen H, Roberts C, Dekker GA, et al. (2013) Non-invasive assessment of maternal hemodynamics in early pregnancy. Pregnancy Hypertens 3(4): 261-269.

18. Tiralongo GM, Lo Presti D, Pisani I, Gagliardi G, Scala RL, et al. (2015) Assessment of total vascular resistance and total body water in normotensive women during the first trimester of pregnancy. A key for the prevention of preeclampsia. Pregnancy Hypertens 5(2): 193-197.

19. Khalil A (2015) Maternal systemic circulation in normotensive pregnancies and those complicated by preeclampsia. Hypertens pregnancy 5(1): 11.

20. Mabuchi A, Yamamoto R, Ishii K, Kakubari R, Takaoka S, et al. (2016) Significance of high-normal blood pressure during early second trimester for predicting the onset of hypertensive disorders in pregnancy. Hypertens Pregnancy 35(2): 234-241.

21. Block-Abraham DM, Adamovich D, Turan OM, Doyle LE, Blitzer MG, et al. (2016) Maternal blood pressures during pregnancy and the risk of delivering to small-for-gestational-age neonate. Hypertens Pregnancy 35(3): 350-360.

22. Black MH, Zhou H, Sacks DA, Dublin S, Lawrence JM, et al. (2015) Prehypertension prior to or during early pregnancy is associated with increased risk for hypertensive disorders in pregnancy and gestational diabetes. Journal of hypertension 33(9): 1860-1867.

23. Stott D, Nzelu O, Nicolaides k, Kametas N (2018) Maternal haemodynamics in normal pregnancies and in pregnancies affected by pre-eclampsia. Ultrasound Obstet Gynecol 52(3): 359-364.

24. Foo FL, Collins A, McEniery CM, Bennett PR, Wilkinson IB, et al. (2017) Preconception and early pregnancy maternal haemodynamic changes in healty women in relation to pregnancy viability. Hum Reprod 32(5): 985-992. 


\section{Your next submission with Juniper Publishers will reach you the below assets}

- Quality Editorial service

- Swift Peer Review

- Reprints availability

- E-prints Service

- Manuscript Podcast for convenient understanding

- Global attainment for your research

- Manuscript accessibility in different formats ( Pdf, E-pub, Full Tsext, Audio)

- Unceasing customer service

Track the below URL for one-step submission https://juniperpublishers.com/online-submission.php 